\title{
The Role of Indigenous Land Management Practices to Improve Crop Productivity in Abobo District, Gambella, Ethiopia
}

\author{
Simeneh Demissie \\ Gambella University \\ Wasihun Mengiste \\ Gambella University
}

\begin{abstract}
The study area is experiencing lack of proper land management practices. Large areas are cleared from vegetation and traditional land management practices are not supported by training and new technologies. The objective of this study was to assess the role of Indigenous Land Management Practices improve crop productivity in Abobo District, Gambella, Ethiopia. The data were gathered through semi-structured questionnaires interviews, field observation, focus group discussion, and key informant interview. A total of 138 households were interviewed randomly from three kebeles. Data collected was organized and analyzed using Micro soft excel and SPSS version 21 . The findings show that about $63 \%$ of the respondents were males while $51.4 \%$ of them literate and $48.6 \%$ were illiterate. From sampled HHs $62.8 \%$ of them got extension service on different LM practices. Most commonly applied LM practices in the study area were application of organic manure, crop rotation, agro forestry, crop residue, fallowing which accounts $55.8 \%, 71 \%, 77.5 \%, 85.5 \%$, and $52.2 \%$ and respectively. These indigenous LM practices improve the fertility level of the soil and as a result increase crop yield. The study areas HHs are not well educated so their LM practices must be supported by trainings and for the yield reduction soil test recommendation should be applied.
\end{abstract}

Keywords: Abobo, Indigenous, LM practices, Land degradation, Soil erosion and soil fertility

DOI: $10.7176 / \mathrm{JEES} / 9-6-04$

Publication date:June $30^{\text {th }} 2019$

\section{INTRODCTION}

Ethiopia, with a land area of 1.12 million $\mathrm{km}^{2}$, possesses a great diversity of terrain, climate, soil, flora and fauna (Teshome, 2013). The country's highland areas include about $90 \%$ of its arable lands and are occupied by 90 percent of the human population and 60 percent of all livestock (Adugnaw, 2014). It includes 95\% of the cropped area and $75 \%$ of the countries livestock (Tsegaye, 2007). The agriculture sector in Ethiopia is a fundamental instrument for poverty alleviation, food security, and fueling economic growth (Kassie, et al., 2009), which accounts for $46 \%$ of the gross domestic product (GDP), $85 \%$ of employment and $90 \%$ of the export earnings (FAO, 2011). Future overall country development is also expected to be driven by the progress in the agricultural sector. Ethiopia's strategy for sustaining the rapid and broad based growth path hinges on maintaining agriculture as a major source of economic growth (MoFED, 2010). However, lack of adequate nutrient supply, the depletion of soil organic matter, and soil erosion are major obstacles to sustained agricultural production (Kassie, et al., 2008).

All over the world, land users are required to maximize the economic and social benefits from the land while fighting against land degradation and desertification (Schwilch, G., et al., 2012). Sustainable land management (SLM) practices are needed to avoid land degradation. Land degradation typically occurs because of land management practices or human development that is not sustainable over a period of time (WMO, 2005).

Abobo District community is experiencing lack of proper land management practices. In the District large areas are cleared from vegetation. The role of indigenous land management technologies and practices, which haven't been supported by research finding, were not yet recognized and scale up to transferred for the farming communities. The productivity of land is reduced from time to time as a result of poor land management practices. The research gaps were not well studied before and indigenous land management technologies are not identified and supported by scientific ways and suggested in the study areas. Therefore, the above points are the main problem areas in which the research tried to give answers. The objectives of this study are

$>$ To identify and evaluate the role of indigenous land management practices

$>$ To evaluate effects of adopted indigenous biological and physical land management practices on the productivity of crop in the study area

\section{MATERIALS AND METHODS}

2.1 Description of the study area

Gambella People's Regional State is one of the nine regions, which constitute the Federal Democratic Republic of 
Ethiopia. It is located in the South-west part of the country, at a distance of $777 \mathrm{~km}$ from Addis Ababa (Hailemariam et al., 2011). The study area, Abobo District is one among the five District s of Agnwa zone found in Gambella People's Regional State (Bisrat, 2011). The study area, Abobo, is located at $42 \mathrm{~km}$ south of Gambella town and about $808 \mathrm{~km}$ West of Addis Ababa. It lies between $07^{0} 50^{\prime} 47^{\prime \prime}$ to $08^{0} \quad 01^{\prime} 59^{\prime \prime} \mathrm{N}$ and $34^{0} 28^{\prime}$ '59" to $34^{0} 34^{\prime} 37$ " E with altitude ranging from 446 to 490 masl and slope gradients ranging from level $(0.2-0.5 \%)$ to gently sloping (2-5\%) (Teshome, 2013).

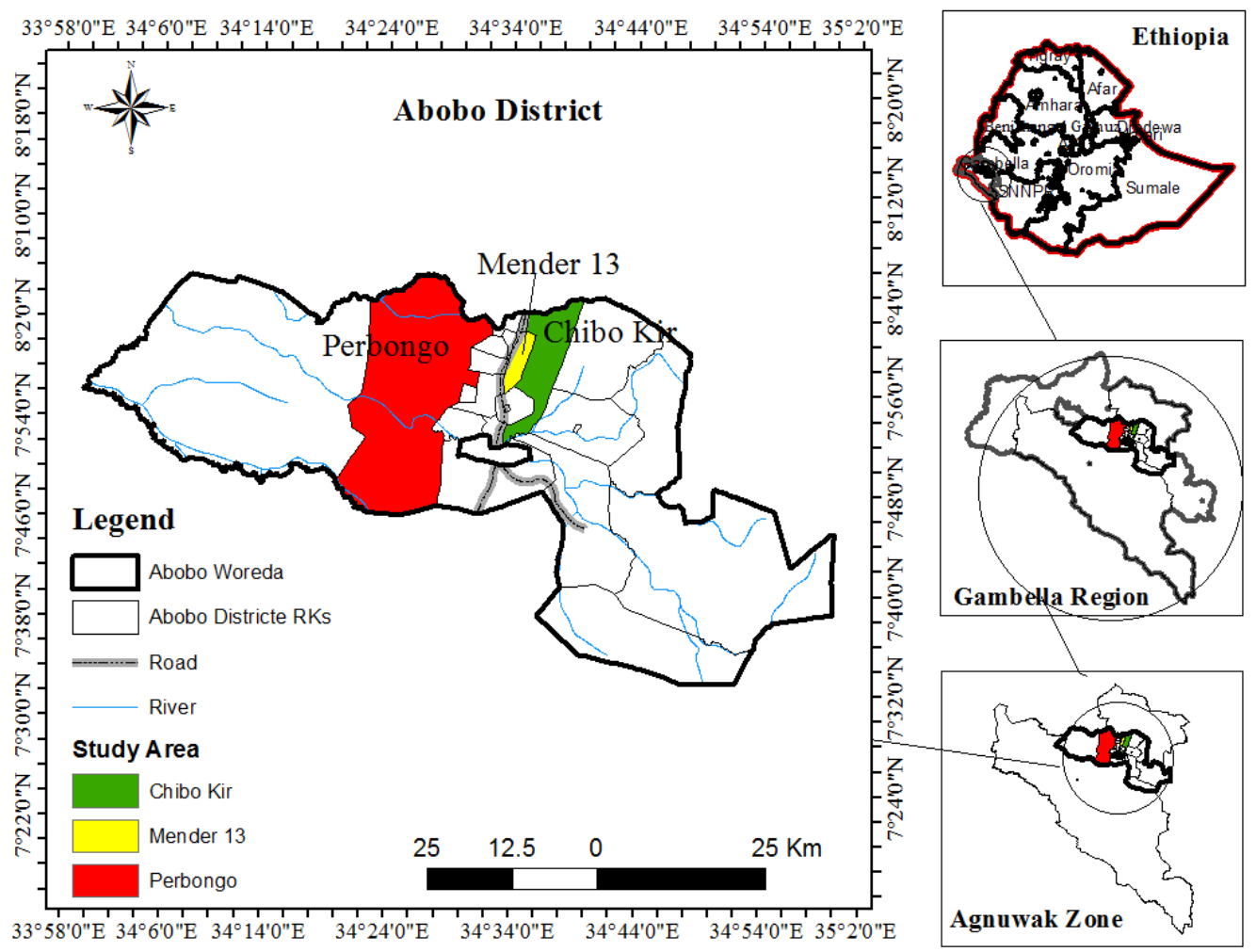

FIGURE1: LOCATION OF THE STUDY AREA.

\subsection{Sampling Methods and Data Collection}

In order to achieve the intended objectives the data for this study was collected from both primary and secondary data resources. The primary data was collected from sample respondents through structured and semi structured questionnaire. The questionnaire was cover various aspects of all land management practices mainly soil and water conservation, cause of land degradation and soil erosion, soil fertility management, demographic and socio economic aspects that directly and indirectly affect land management practices. The questionnaires were prepared in English but at the time of interview it was translated into local language.

In this research farmers and, field observation, were the major sources of primary data. In order to ensure the reliability and validity of the data collection, triangulation of different methods was conducted during collection of primary data. These methods include field observation, focus group discussion; transect walk, and other key informant interview.

\subsection{Determination of Sample Size and sampling technique}

Prior to determining sample size of the study the area three kebeles were selected randomly. For each kebele sample house hold members are selected by simple random sampling technique. Based on the 2007 Census conducted by the CSA, this District has a total of 15,741 population and the total household heads residing in the area is 3,867 . Following this, total sample size was determined using the following formula (Cochran, W. G. 1977).

$$
\begin{aligned}
& \text { area is 3,867. Following this, total sample size was determined using the following formula (Cochran, W. G. 1977). } \\
& n=\frac{\mathrm{N}_{0}=\frac{\mathrm{z}^{2} \mathrm{pq}}{\mathrm{d}^{2}}}{1+\frac{\left(n_{0}-1\right)}{N}}
\end{aligned}
$$

Where, 
$\mathrm{N}_{0}=$ the desired sample size when the population is greater than 10000

$\mathrm{n}=$ number of sample size when population is less than 10000

$Z=95 \%$ confidence limit i.e. 1.96

$\mathrm{P}=0.1$ (proportion of the population to be included in the sample i.e. $10 \%$ )

$\mathrm{q}=1-0.1$ i.e. $(0.9)$

$\mathrm{N}=$ is total number of population

$\mathrm{d}=$ margin of error or degree of accuracy desired $(0.05)$

Based on the above sample size determination formula the sample size is calculated gives as 138 farmers. Accordingly, from each kebele 46 household heads, was selected and responded.

\subsection{Data Analysis}

Depending on the type of information collected, different analysis methods were applied. Data collected was organized and analyzed using Micro soft excel, SPSS version 21.

\section{Chapter 3. RESULTS AND DISCUSSION}

\subsection{Indigenous Land Management Practices}

The most commonly applied land management practices of the study area are application of organic manure, crop rotation, Agro forestry, crop residue, Fallowing which accounts 55.8\%, 71\%, 77.5\%, 85.5\%, and 52.2\% and respectively (Table 3.1 ).

\begin{tabular}{|c|c|c|c|c|c|}
\hline \multirow[t]{2}{*}{$\begin{array}{l}\text { Types of land management } \\
\text { practices }\end{array}$} & \multicolumn{2}{|c|}{ Awareness to technology } & \multicolumn{2}{|c|}{$\begin{array}{l}\text { Not awareness to } \\
\text { technology }\end{array}$} & \multirow[t]{2}{*}{ Total } \\
\hline & Frequency & Percent & Frequency & Percent & \\
\hline Mixed cropping & 68 & 49.3 & 70 & 50.7 & $138(100)$ \\
\hline Organic manure & 77 & 55.8 & 61 & 44.2 & $138(100)$ \\
\hline Crop residue & 118 & 85.5 & 20 & 14.5 & $138(100)$ \\
\hline Agro forestry & 107 & 77.5 & 31 & 22.5 & $138(100)$ \\
\hline Crop rotation & 98 & 71 & 40 & 29 & $138(100)$ \\
\hline Zero tillage & 44 & 31.9 & 94 & 68.1 & $138(100)$ \\
\hline Fallowing & 66 & 47.8 & 72 & 52.2 & $138(100)$ \\
\hline
\end{tabular}

\subsubsection{Biological land management practices}

Biological land management practice is one of the traditional practices under taken by the local farmers in the study area. Some of the biological land management practices that practiced by the local farmers are as follows.

\section{Crop rotation}

Crop rotation is the cultivation of different crops alternatively. It is the second commonly practice exercised by many farmers as compared to other practices. From the sampled house hold $71 \%$ were practicing crop rotation in their crop field. Farmers practice crop rotation in there agricultural field for soil fertility maintenance, weed and diseases control. This idea is in agreement with the study done by (Adimew, 2014; Tegegne, 2014) farmers at the study area have been using crop rotations that were applied for many years have good understanding of why to rotate crops and well aware that crop rotation can improve soil productivity.

\section{Mixed cropping}

Farmers in the study area traditionally allocate multiple crops at a time or two crops or more which can grow well with no or minimum competition for light, water and nutrient. This aged-old practice has importance in terms of soil fertility improvement, increasing yield and ensuring income in time of disaster. From the total 138 sampled households 68 (49.3\%) of them were used intercropping practices on their field (table3.1). Common intercropping practice in the area involves growing of maize with Pumpkin fruit, cowpeas (Fig. 2).

Even though, farmers practices intercropping mainly to ensure the availability of food from different crops and to obtain animal feed on continuous supply, it also improves soil fertility through crop diversification and provide soil cover to protect the impact of rain drop on soil and minimize erosion which is in agreement with the finding of (MoA, 2001) reported that, the aim of intercropping is to increase productivity of the land and to protect the soil against erosion. 




Figure 2: Mixed cropping system.

\section{Agro - forestry}

Agroforestry refers to land use practices in which woody perennials are deliberately integrated with agricultural crops, varying from very simple and sparse to very complex and dense systems. It embraces a wide range of practices (e.g. farming with trees on contours, intercropping, multiple cropping, bush and tree fallows, establishing shelter belts and riparian zones/buffer strips with woody species etc.) which can improve land productivity providing a favourable micro- climate, permanent cover, improved soil structure and organic carbon content, increased infiltration and enhanced fertility (WOCAT, 2011). In the study area integrate fruit tress (mango trees and avocado fruit) are often grown with crops near to their home stead. The reason why farmers pay more attention for fruit trees are because of their multi benefits, one for the income through sale of products, and the other is environmental benefits that enhance the cropland productivity by increasing the infiltration and by controlling the runoff and soil erosion. In addition agro forestry has benefits in the study area source of food, conserving and enriching the soil, protecting crops and animals against extreme temperatures, and provision of wood, fuel and fodder. From the total138 sampled households only 107 (77.5\%) of them were practiced agroforestery in their farmland specifically near to their homestead. The states of traditional biological land management practices by sampled HHs presented in (Fig. 3).

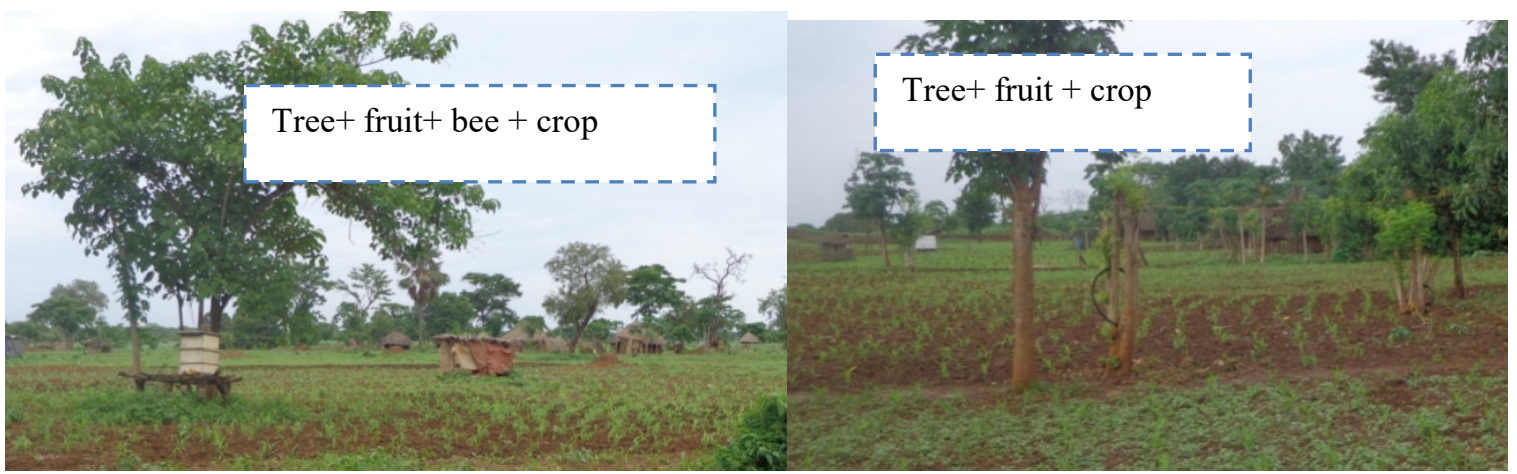

FIGURE3. AGROFORESTRY PRACTICES IN THE STUDY AREAS.

\subsubsection{Physical land management practices \\ Contour farming}

This consists of cultivating the land on or close to the contour instead of up and down the slope or round and round the field. When this is done, each furrow acts as a small dam, catching water as it runs down the hill and encouraging it to soak into the soil (fig 5). This simple conservation measure may be enough by itself to prevent the runoff of water and erosion where slopes are gentle and the rainfall intensities are low. Such land management practices were also supported with shileshal furrows. In the shileshal furrows (furrows with interval) there is distance between successive furrows (fig 5). In these types of furrow the lower furrow doesn't filled by the soil from the upper furrow. As a result the shileshal furrows have high capacity to reduce run off rate and large volume of water can inundated in the furrow. 


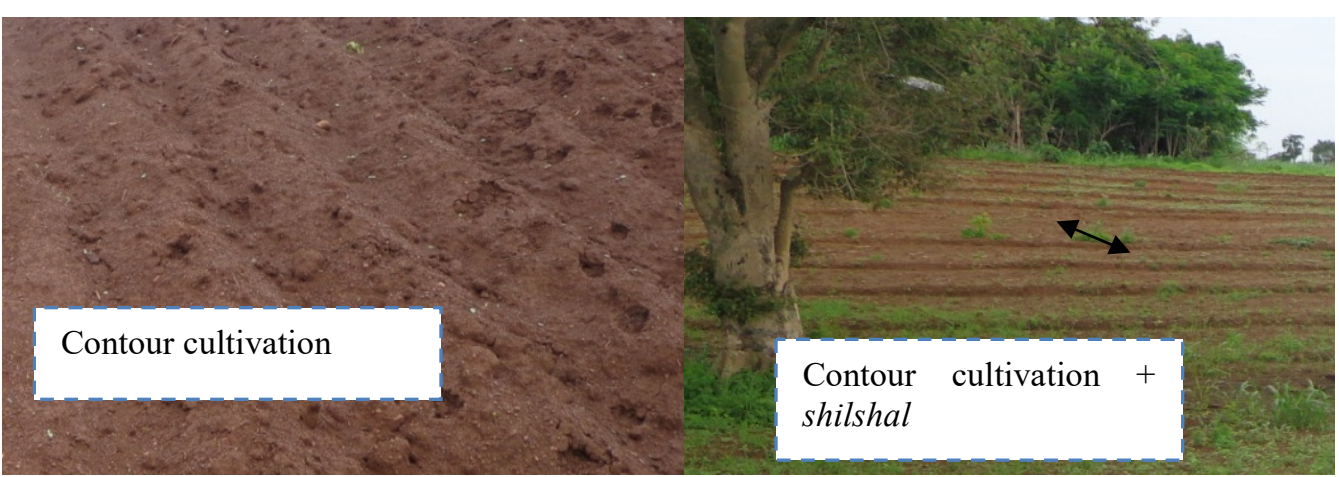

Figure 4. Contour furrows

Figure 5. Contour cultivation and shileshal.

\section{Residue Management}

Residue management is one of traditional practices in which crop residues are left on farmland, recycled until the last date of planting and used as mulch. Crop residue as indicated in the (Fig 6) below ranked first, which has been practiced by majority of, sampled households. Currently, 118 (85.5\%) of the households were adopted to practice residue recycling on their farm fields for soil fertility improvement, which adds organic matter to the soil and increases moisture retention capacity of the soil.

Crop straw, Maize and sorghum stalks are among crop residues used as soil mulch in protecting soil moisture lose during dry season, intercepts rain drops impacts from striking soil surface and contribute in reducing run off.

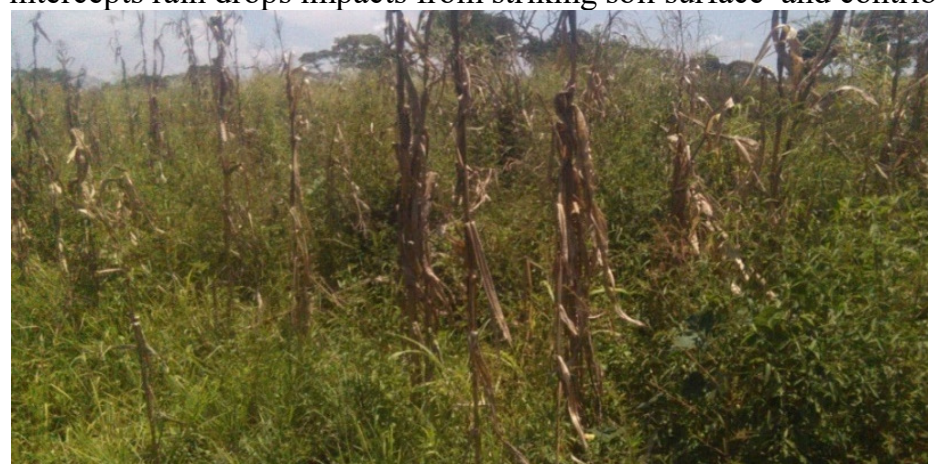

Figure 1. Crop residue left after crop harvested.

\section{Tillage practices}

Shalla cultivation is a traditional land preparation system done by slashing and hoeing the land to sow crops with low disturbance of the soil. This type of land preparation mainly practiced by Anuak people mostly done near to the homestead in small plots of land. Most highlanders used oxen to plow their lands. In the shalla cultivation system there is low disturbance of soil and big trees are not completely cleared from the farm land. The (fig.8) indicates maize crop planted by shalla cultivation system.

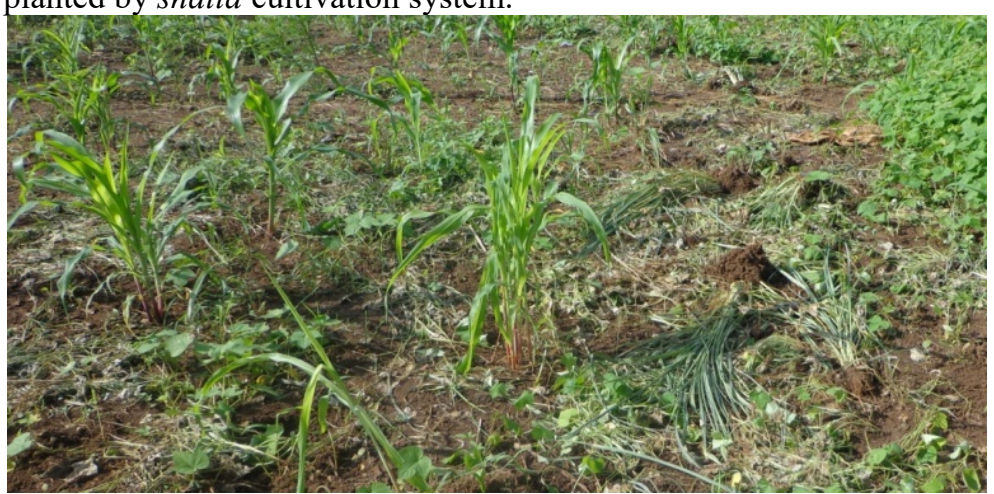

Figure 2. Maize planted by shalla cultivation.

\section{Weeding practices}

Weeds are plants growing out of places. It may cause yield reduction. In the study area most farmers practice weeding to reduce competition of nutrient and other resources between crops and the weeds. Here the special thing to land management is that, farmers spread weeds on the surface of crop land after weeding (fig 10). This practice 
reduce nutrient loss as weed removal, and used as a mulch (reduce soil erosion, further weed growing and conserve soil moisture).

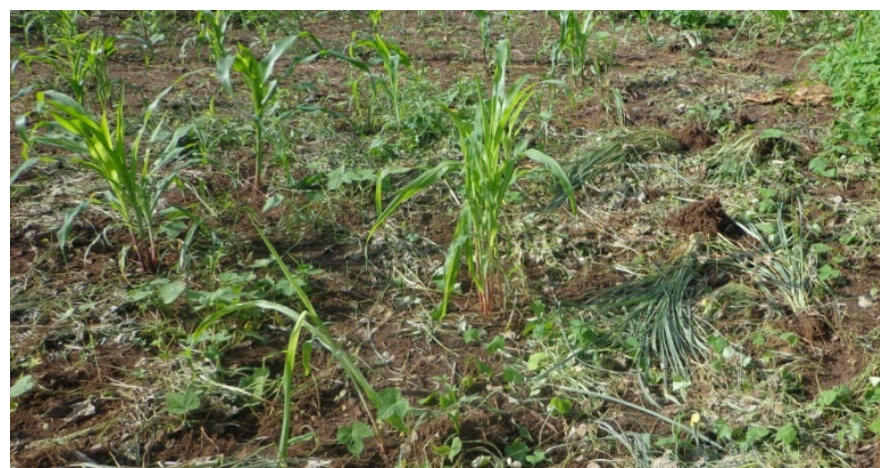

Figure 3. Weeds were spread under maize crops.

\subsection{Evaluate effects of adopted indigenous LM practices on the productivity of crop}

The fertility level of farmland in the area was assessed by using household interview. Most of the farmers, $83.3 \%$ of the cases, responded their soil fertility status being under medium level (Table 3.2). Only $1.4 \%$ of the respondents perceived their farm land fertility status were low level.

TABLE 3.2 SOIL FERTILITY LEVEL OF FARMER'S FARM LAND

\begin{tabular}{lccc}
\hline Soil fertility level & Frequency & Percent & Cumulative Percent \\
\hline High & 21 & 15.2 & 15.2 \\
Medium & 115 & 83.3 & 98.6 \\
Low & 2 & 1.4 & 100.0 \\
Total & 138 & 100.0 & \\
\hline
\end{tabular}

There are several soil fertility improvement mechanisms which are commonly practiced by farmers of the study area. In the discussions, farmers were asked to identify their own indigenous methods of improving the fertility conditions of the soils on crop lands. Thus, farmers have described their practical farming experiences with regard to traditional fertility improvement practices. The greater crop yield obtained from land with appropriate land management practices due to maintaining availability of plant nutrients. The practices provides soil cover and protect from the impact of rain drops and reduces runoff and adds organic matter by its biomass decomposition as a result nutrients are more available to the crop. Less crop yield obtained in the absence of indigenous land management practices due to the removal of plant nutrient by soil erosion and crop harvest without replacement by adequate land management practices. Therefore, traditional land management practices have a role to play in increasing crop yield by adding and maintain the available nutrient in the soil and enable the crop to take it on a continuous base. Yield difference showed that soil with indigenous land management practices have greater by $22.85 \%$ and $21.35 \%$ for maize and sorghum yield than soil without indigenous land management practices.

The importance of fertilizer as an agricultural input cannot be over emphasized by development agents and District experts in the study area. Crops require fertilizers in sufficient amount to give the maximum economic returns. Due to farmer's lack of access inorganic fertilizers in the market they used different organic fertilizers to increase crop yield. The most commonly used organic fertilizers by the farmer in the study area are compost $(18.7 \%)$, farm yard manure $(43.5 \%)$, green manure $(31.9 \%$ and crop residue $(54.3 \%)$ fig 12 .

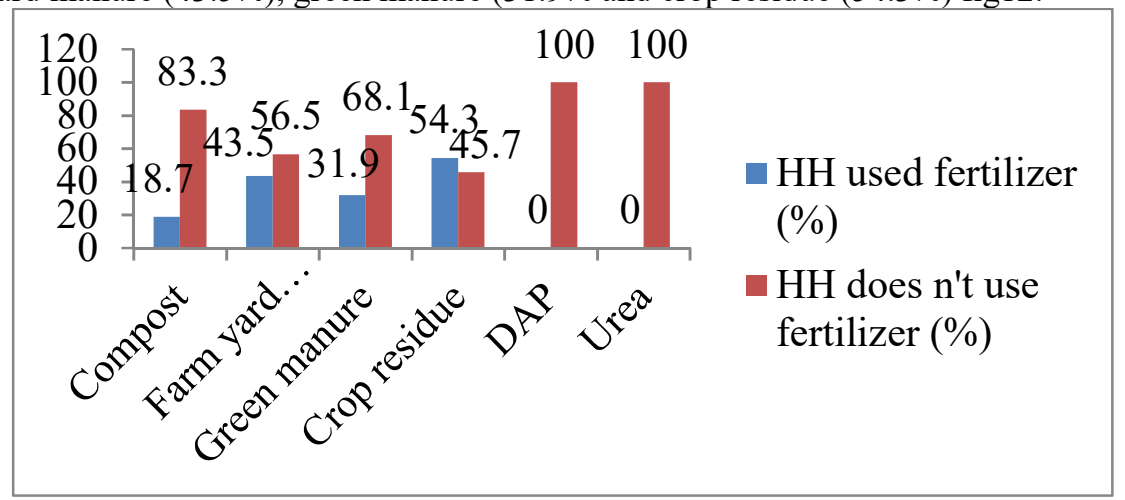

Figure4. Types and levels of fertilizer use by the sampled households. 


\section{Chapter 4. CONCLUSIONS AND RECOMMENDATIONS \\ 4.1. Conclusions}

The research finding indicates that the most commonly practiced indigenous land management practices in the study area are application of organic manure, crop rotation, agro forestry, crop residue, fallowing, mixed cropping, Contour farming, Shalla cultivation, and weeding practice. These indigenous land management practices are very important to ensure sustainable land management and to increase crop yield per plots of land.

The finding of the study revealed that indigenous biological and physical land management practices have been improving cropland productivity. The fertility level of household farm land depends on inherit nutrient holding capacity of the soil and farmers land management practices. The reason for soil fertility differences are due to adoption of a set of indigenous LM practices on the farm land.

\subsection{Recommendations}

$>$ Local farmers have limited access to training and extension services on different land management practices. Training and experience sharing program should be given to the local farmers on use of traditional land management practices for up scaling.

$>$ A combination of traditional biological and physical land management practices should be practiced for effective cropland improvement.

$>$ The fast growing elephant grass highly disturb the agricultural practices of local farmers (difficult to cultivate the land) so further research needed to reduce the growth of this difficult grass species.

$>$ In the blanket recommendation the study area households do not access to use artificial fertilizer but, crop yields reduced from time to time so fertilizer should be available to local farmers in the market and applied to the soil based on the soil test recommendation.

$>$ To reduce the mobility of local community from place to place, introduce permanent fruit trees around their homesteads.

\section{REFERENCES}

Adimew Admasie, 2014. Assessing Integration of Indigenous practices with Modern Technologies for Sustainable Land Management: the Case of Soil Conservation and Fertility Improvement in Debremitmak Kebele, East Gojjam. In Partial Fulfillment of the Requirements for the Degree of Masters of Geography, Addis Ababa university.

Adugnaw Birhanu, 2014. Environmental Degradation and Management in Ethiopian Highlands: Review of Lessons Learned. International Journal of Environmental Protection and Policy. Vol. 2, No. 1, pp. 24-34. doi: 10.11648/j.ijepp.20140201.14

Bisrat Worku, 2011. Impact of resettlement on the livelihood of settler population in abobo District, gambella people's regional state. A thesis submitted to the school of graduate studies of Addis Ababa university in partial fulfillment of the requirements for the degree of master of science in population studies.

Cochran W., 1977. Sampling Techniques. $3^{\text {rd }}$ ed. John Wiley and sons. USA.

FAO, 2011.Climate-Smart Agriculture: A Synthesis of Empirical Evidence of Food Security and Mitigation Benefits from Improved Cropland Management. Mitigation of climate change in agriculture series 3

Hailemariam Behailu, Mulugeta Tsedal, Ali Jemal, Galuak Katckos, Riek Weshik, Gezachew Asere, Tesfay Haile, Asefaw banjo, Zelalem Wasihun, Umod Umode, 2011. Action plan of adaptation to climatic change." Gambella Ethiopia.

Kassie, M., Pender J., Yesuf M., Köhlin G., Bulffstone R., and Mulugeta, E., 2008. Sustainable land management practices improve agricultural productivity: evidence on using reduced tillage, stone bunds, and chemical fertilizer in the ethiopian highlands. Policy brief sustainable land management and agricultural productivity.

Kassie, M., Zikhali, P., Pender, J., and Köhlin, G., 2009. "Sustainable Agricultural Practices and Agricultural Productivity in Ethiopia: Does Agro-ecology Matter?” EfD Discussion Paper 09-12, a joint publication of Environment for the Development Initiative and Resources for the Future (www.rff.org), Washington DC.

Ministry of Finance and Economic Development (MoFED). 2010. The Federal Democratic Republic of Ethiopia Growth and Transformation Plan (GTP) 2010/11-2014/15. Addis Ababa, Ethiopia.

MoA (Ministry of Agriculture), 2001. Soil and water conservation manual/guide for Ethiopia. Adiss ababa, Ethiopia.

Schwilch G., Hessel, R. and Verzandvoort S., 2012. Desire for greener land. options for sustainable land management in drylands. Bern, Switzerland, and Wageningen, The Netherlands: University of Bern - CDE, Alterra - Wageningen UR, ISRIC - World Soil Information and CTA - Technical Centre for Agricultural and Rural Cooperation.

Tegegne Tatek Belay, (2014). Perception of Farmers on Soil Erosion and Conservation Practices in Dejen , Ethiopia. International Journal of Environmental Protection and Policy. Vol. 2, No. 6, , pp. 224-229. doi: 
10.11648/j.jijepp.20140206.15

Teshome Yitbarek, 2013. Soil Survey, Impacts of Land Use on Selected Soil Properties and Land Suitability Evaluation in Abobo Area, Gambella Regional State of Ethiopia. A PhD Dissertation Submitted to the School of Natural Resources and Environmental Science, School of Graduate Studies Haramaya University.

Tsegaye Birkneh, 2007. Assessment of Land Degradation Using GIS Based Model and Remote Sensing in Bishan Guracha-Adilo Subcatchments, Southern Ethiopia. A Thesis Submitted to the School of Graduate Studies of Addis Ababa University, in Partial Fulfillment of the Requirements for the Degree of Master of Science in Geographic Information System and Remote Sensing, pp. 86

World Meteorological Organization (WMO), 2005. Climate and Land Degradation. World Meteorological Organization -No. 989 ISBN 92-63-10989-3; pp1-32

WOCAT, 2011. "Database on SLM Technologies." Retrieved January, 2011, fromhttp://www.wocat.net/. 